\title{
Não é para ser lido, é para ser curtido: Rogério Duarte e Flor do Mal
}

\author{
Isabela Marques Fuchs ${ }^{1}$
}

Resumo: Este artigo tem como proposta destrinchar a relação "arte e vida" entre o impresso alternativo e marginal "Flor do Mal" de 1971, que circulou nos grupos contraculturais cariocas neste período, e o seu correspondente designer gráfico, Rogério Duarte, no contexto da Marginália, esgotamento do projeto tropicalista e acirramento do cerceamento às atividades artísticas no Brasil.

Palavras-chave: impressos alternativos, marginália, design brasileiro, contracultura

\section{Meant not to be read, but to be enjoyed: Rogerio Duarte and Flor do Mal}

Abstract: This article has as its proposal the unraveling of the relation between art and life on the alternative and marginal magazine "Flor do Mal" (1971), that circulated between the cariocas countercultural circles of this time, and its corresponding graphic designer, Rogerio Duarte, in the context of Marginalia, the exhaustion of the tropicalista project and the tightening of censorship to artistic activities in Brazil.

Keywords: alternative press, marginalia, brazilian design, counterculture

1 Doutoranda em História na Universidade Federal de Santa Catarina, na linha de pesquisa Subjetividade, Gênero e Poder, onde pesquisa sobre as representações de mulheres vinculadas à democracia e direitos humanos nos impressos alternativos entre 1974 e 1979. Mestra em História pela Universidade Federal do Paraná, onde defendeu a dissertação intitulada «Design e Resistência Cultural: A Linguagem de Rogério Duarte (1962-1971)» sob a orientação do Prof ${ }^{\circ}$ Dr. Artur Freitas. É membra do Laboratório de Estudos de Gênero e História, onde participou do projeto «Mulheres de luta: feminismo e esquerdas no Brasil (1964-1985)" e participa do projeto «Políticas da Emoção e do Gênero». Universidade Federal de Santa Catarina, UFSC. E-mail: isa.fuchs@gmail.com. Lattes: http:// lattes.cnpq.br/4050842999779849. Florianópolis, Brasil 
Uma revistinha em preto e branco cheia de colagens, textos, fotografias, tudo feito à mão. Relativamente pouco conhecida pela historiografia, a Flor do Mal foi uma revista que circulou em 1971 nos núcleos contraculturais cariocas. Contando com a participação criativa de Tite Lemos, Torquato Neto, Luiz Carlos Maciel, Waly Salomão, Dicinho, Rogério Duarte e seus respectivos amigos conhecidos de clínicas psiquiátricas, Flor do Mal tinha em suas páginas poesias e demais textos caleidoscópicos em prosa. Fundiase espiritualismos, religiosidades, juntamente com relatos pessoais.

Para os limites deste texto, interpretarei pontualmente a participação de Rogério Duarte na produção deste impresso. Rogério era o responsável pelo projeto gráfico da primeira edição de Flor do Mal, articulando seus aspectos visuais com suas experiências de vida; em seu traço e em escolhas formais havia uma relação com os seus conceitos políticos, comportamentais e espirituais. Rogério desejava que a revista fosse completamente feita à mão, com uma equipe de calígrafos tal qual na Idade Média $^{1}$. O procedimento adotado no projeto da Flor do Mal era o de um vigor artesanal, priorizando fotos recortadas, escritas em caligrafia à mão, entre os textos que mesclavam o fim da Era de Peixes, androginia e música pop. Buscava-se algo fora do espectro real, indo mais para uma experiência surrealista e espontânea, conectando-se a uma liberdade total².

Iniciarei o texto com apontamentos sobre Rogério Duarte, com uma pequena biografia de sua trajetória de pensamento do início da década de 1970, que coincide com o seu período de pós-prisão e necessidade de se exilar no interior baiano. Marginalidade cultural e misticismos são duas palavras-chave para entender seu processo de vida. Em seguida, abordarei as implicações estético-políticas de sua vivência, junto com a trajetória e o conceito de Marginália. Por fim, serão apresentados os aspectos formais e imaginativos das páginas de Flor do Mal.

\section{Rogério Duarte: Coragem para suportar}

Rogério Duarte, convidado a ser o designer gráfico de Flor do Mal, já era uma figura bastante conhecida nos círculos artísticos, principalmente na

1 CABO, Júlia Souza. Flor do Mal, cultura marginal e heterotopias. XXVII Simpósio Nacional de História. Natal. 2013, p.7

2 KUCINSKI, Bernardo. Jornalistas e Revolucionários: nos tempos da imprensa alternativa. 1a edição. São Paulo: Editora Página Aberta, 1991, p.52. 
tropicália. Rogério Duarte inseriu-se na tropicália como um dos autores de sua visualidade. Amigo próximo de Caetano Veloso, Gilberto Gil e Hélio Oiticica, Rogério acreditava que "falar de qualquer coisa dessa época é um pouco falar de mim e da minha turma. A nossa turma. O espírito do tempo é essa geração de pessoas que estavam todas de uma maneira ou outra, interligadas"3. Ele foi o capista do álbum Caetano Veloso, lançado no início de 1968, e Gilberto Gil, de mesmo ano, dois discos que sintetizavam o imaginário tropicalista, com as músicas "Tropicália", "Alegria, Alegria”, "Marginália II" e "Coragem para suportar" para dar alguns exemplos.

Um agitador cultural, ex-membro do Centro Popular de Cultura da União Nacional dos Estudantes (CPC daUNE), próximo dos artistas "desbundados", ligado às esquerdas. Em 1968, esta seria uma descrição própria para Rogério Duarte. Ele fez parte da massa de pessoas que compareceu à fatídica missa de sétimo dia do secundarista Edson Luís, morto no restaurante Calabouço por militares. Rogério e seu irmão foram presos por policiais à paisana, colocados à força em uma kombi. O sumiço foi amplamente reportado na imprensa ${ }^{4}$ até eles serem finalmente encontrados. Nos jornais, lia-se: "Êles voltaram como se viessem do inferno. Foram 8 dias de tortura estilo chinês, interrogatórios imbecis, ameaças e humilhações (...) Eles só tinham um crime: usar barba" ${ }^{5}$. Eles tinham sido soltos no dia 12 , e no momento de sua soltura os militares haviam os advertido de que eles seriam um exemplo para intelectuais, jornalistas e artistas e, caso denunciassem algo, estariam arriscando a sua vida ${ }^{6}$.

Na prisão, perguntavam a Rogério se ele andava com os artistas que se opunham à censura, se ele era artista, perguntaram-lhe os nomes dos "outros agitadores”, sempre sentado no chão gelado e com as mãos amarradas:

- Que acha de Guevara? Estudante fazer agitação na rua. Acha certo? Que acha dos conflitos raciais? Os comunistas querem destruir nossas tradições, você acha isso certo? Ah! É isso então o que eles querem. O ideal da revolução é esse? Da próxima

3 DUARTE, Rogério, 2015. In.: LIMA, José Walter. O Tropikaoslista [Filme]. Rio de Janeiro, 2015. Digitalizado.

4 Autoridades continuam negando a prisão de cineasta e de seu irmão. Tribuna da Imprensa. 12 abr. 1968; Paradeiro dos irmãos Duarte continua ignorado. Jornal do Brasil. 12 abr. 1968; Silvia Escorel viu SNI levar os cineastas. Tribuna da Imprensa. 10 abr. 1968.

5 Irmãos Duarte apareceram: 8 dias de tortura chinesa. Diário de Notícias, 14 abr. 1968.

6 Ibidem. 
vez, o inferno. Disseram. Digam isso à esquerda festiva ${ }^{7}$.

Anos depois, em entrevistas, Rogério relatou que nunca ficavam no mesmo lugar, viajando horas de carro sem saber onde estavam ${ }^{8}$. O medo da morte era recorrente, e os militares afirmavam que iriam fuzilá-los. Rogério acreditava que sua prisão não era para ser mais uma, mas sim algo exemplar, para assustar. Segundo ele, os militares planejaram matá-lo e jogar seu corpo no Rio Gandu, no Rio de Janeiro. Só não aconteceu porque, pressupunha ele, a imprensa teve um papel importantíssimo de denúncia e ele e seu irmão tinham relações muito importantes com políticos, como o senador Josaphat Marinho, por exemplo9. De todo modo, ele dizia que 1968 foi o ano de sua morte, de seu assassinato: "Sou um cara destruído pela ditadura, mesmo, pelo menos em termos da minha obra", Rogério lhes disse ${ }^{10}$.

Suas denúncias públicas aos militares talvez tenham sido o principal motivo pelas ameaças de morte que ele estava recebendo em dezembro de 1968, poucos dias antes de vigorar o Ato Institucional $n^{\circ} 5^{11}$. Ele decidiu, por bem, ir para Feira de Santana, cidade localizada a mais de cem quilômetros da capital baiana, ficar na chácara de seu pai, um rico eletricista da região. Ele não conseguia sequer sair de seu quarto, por medo, ansiedade e depressão ${ }^{12}$. Embora fosse um tempo de reclusão, Rogério ainda conseguiu produzir algumas peças gráficas até voltar ao Rio de Janeiro em 1970, como a capa do disco Gilberto Gil (1969) e o cartaz do filme Meteorango Kid (1969).

Seu exílio coincidiu com o de outros artistas da época. Gil e Caetano tinham ido a Londres; Geraldo Vandré, Taiguara e Chico Buarque, Ferreira Gullar, Glauber Rocha, Augusto Boal e Hélio Oiticica que se exilaram e retornaram ao Brasil entre os anos 1970 e 1976. Nem todos os artistas brasileiros quiseram

7 DUARTE, Rogério. A Grande Porta do Medo, 1968. In.: COHN, Sergio. Encontros: Rogério Duarte. 1a edição. Rio de Janeiro: Beco do Azougue, 2009, p.51.

8 DUARTE, Rogério. 0 tropicalismo transcende a música. Entrevista cedida à Roberto Midlej. A Tarde, 21 set. 2008.

9 Ibidem.

10 DUARTE, Rogério. Tropicália reprimida. Entrevista cedida à Pedro Alexandre Sanchez. Folha de São Paulo, 28 abr. 2003.

11 DUARTE, Op.cit, 2015.

12 DUARTE, Rogério. Tropicaos. 1a edição. São Paulo: Azougue Editorial, 2003. p.67. 
(ou foram obrigados a) sair de seu país. De toda forma, os que optaram por permanecer em seu país ficaram sujeitos a uma constante vigilância.

A resistência a ditadura militar não se abateu após a instalação dos "anos de chumbo". Os artistas buscaram novas formas de trabalhar, sendo a MPB a "área mais resistente da produção cultural" do começo dos anos 1970, com os shows em universidades e em circuitos menores do que as grandes emissoras de televisão ${ }^{13}$. Evidente que a censura era pungente, bem como a auto-censura: os artistas que desejavam gravar suas músicas eram obrigados a encaminhar as letras para o Serviço de Censura Federal, o que fazia com que os artistas muitas vezes fizessem suas músicas sob pseudônimos, ou nem gravá-las ${ }^{14}$. Rogério, por exemplo, não utilizava seu sobrenome para se identificar nas informações técnicas dos trabalhos que realizou entre 1968 e 1971; nas informações técnicas do álbum Gilberto Gil (1969), localizadas na parte traseira do encarte, aparece apenas o nome Rogério, sem sobrenome, para identificar quem fez o projeto gráfico da capa.

No início dos anos 1970 Rogério abateu-se em uma crise depressiva forte, tendo de voltar para o Rio de Janeiro para se tratar em hospitais psiquiátricos, por incentivo de amigos e familiares. Foi diagnosticado como esquizofrênico, com demência precoce ${ }^{15}$ e com psicose maníacodepressiva, tendo feitos tratamentos lobotômicos com o uso de camisa-de-força, com a sua autorização e plena consciência ${ }^{16}$. Sua alta do Hospital das Clínicas veio no mesmo dia em que Caetano e Gil voltaram de seu exílio em Londres. Assim que os cantores chegaram, Rogério e Gil foram morar juntos. Dentre as coisas que compartilhavam, sobressaiam-se os estudos em esoterismo, ocultismo e espiritualidade.

O cruzamento de Rogério com a espiritualidade foi, em suas palavras, um "meio de evitar o enloquecimento total", e não exatamente um misticismo. Por outro lado, Rogério negou que a sua religiosidade fosse fruto de sua opressão perante ao aparelho repressor ${ }^{17}$. Ele, que lia a Bíblia e sentiu ter

13 DUNN, Christopher. Brutalidade Jardim: A tropicália e o surgimento da contracultura brasileira. São Paulo: Unesp, 2009. p.187.

14 Ibidem, p.189.

15 DUARTE, Op.cit, 2003, p.34.

16 Ibidem.

17 DUARTE, Rogério. Tropicália revisitada. Entrevista cedida à Ana de Oliveira. 2007. 
entrado em transe após uma leitura exaustiva do Pai Nosso, andava no Rio de Janeiro com um crucifixo inscrito "INRIO", um trocadilho com "INRI", acrônimo de "I|sus Nazar|nus, R Rx ||dae|rum", no português "Jesus de Nazaré, Rei dos Judeus". A religiosidade de Rogério, de acordo com o mesmo, perdurou anos após a sua prisão e tratamentos psiquiátricos. Para ele, antes de uma fuga material, foi uma busca pelo seu inconsciente, um "mergulho dentro de si mesmo" que perdurou por toda sua vida ${ }^{18}$.

Cansado de passar por hospitais psiquiátricos - já havia sido internado em três - Rogério tentou um novo recurso: o LSD. Seu terapeuta, que era conhecido pela sua experiência com substâncias alucinógenas, the advertiu: "Você não. Você, se tomar, não volta mais. Você não pode tomar

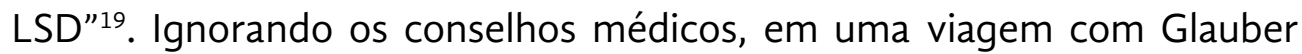
Rocha para Itaparica, na Bahia, ambos tomaram LSD em pó. Rogério Duarte tinha plena certeza de que havia sido curado com o uso de LSD ${ }^{20}$. Deveras, nos anos 1970 circulava a ideia de que

o LSD é um remédio. [...] o mais poderoso dos instrumentos existentes para a análise do psiquismo humano. [...] é o processo de tratamento mais eficaz com que, em toda a história da Medicina, o homem já contou para a terapêutica de uma série de distúrbios psíquicos ${ }^{21}$.

Com fins a encontrar novos modos de percepção e ter experiências psicodélicas, alterações visuais e euforia, houve uma movimentação ao redor das experiências com alucinógenos por parte da juventude da década de 1970. Isso, claramente, alarmou as autoridades brasileiras. O Departamento de Ordem Política e Social (DOPS) afirmava que as drogas eram utilizadas como arma política para atrair a juventude, criar dependência e fazer deles escravos das drogas para torná-los, posteriormente, agentes do comunismo ${ }^{22}$. Não apenas com psicoativos,

Disponível em <www.tropicalia.com.br>. Acesso em: $1^{\circ}$ de abril de 2020.

18 Ibidem.

19 DUARTE, Op.cit, 2015.

20 DUARTE, Op.cit, 1997.

21 Verdades sobre o LSD. O Pasquim. n. 51, 17 jun. 1970.

22 DUNN, Christopher. Contracultura: Alternative Arts and Social Transformation in Authoritarian Brazil. 1 a edição. Carolina do Norte: The University of North Carolina Press, 
mas na época estendiam-se também as descobertas espirituais, religiões orientais, hare krishna, veda anta e a eubiose. De forma semelhante, novas formas de habitar, a convivência em comunidade e a psicanálise eram respostas à dúvida e à crise da intelectualidade ${ }^{23}$.

A "loucura" 24 foi adotada como forma de romper os dogmas racionalizantes e burgueses e, principalmente, para romper com o ideal racional do capitalismo. Iniciou um delineamento progressivo de uma fadiga e desinteresse pela política. A fuga foi tomada em uma posição assumida de transgressão, com valores assumidos como contestação política. Se os artistas foram banidos da possibilidade de atuar nas instâncias permitidas, não fazia sentido a sua atuação em espaços os quais eles não consideravam como legítimos ou que não eram compatíveis ideologicamente.

\section{Marginal, marginália}

Marginália. Para explicá-la torna-se mais fácil primeiramente delinear o amplo fenômeno da contracultura setentista. O termo contracultura é geralmente definido como o conjunto de movimentos de rebelião marcados nos anos 1960 e 1970, um fenômeno situado historicamente, em vez da ideia mais geral de um espírito de contestação que surge de tempos em tempos. Rogério Duarte nos fornece sua visão sobre o fenômeno da contracultura dos anos 1960 e 1970:

Não se pode colocar qualquer movimento dentro da cultura brasileira como algo desvinculado e autóctone (...) tudo é uma imbricação de problemáticas. Aquela música de Caetano em que ele fala "Arrebentar as prateleiras... É proibido proibir!" é uma homenagem ao movimento estudantil na França. A bandeira de Hélio Oiticica, "Seja marginal, seja herói" é o movimento de contracultura, idêntico ao americano, ao francês ${ }^{25}$.

2016, p.27.

23 HOLLANDA, Heloísa Buarque. Impressões de viagem: CPC, vanguarda e desbunde, 1960-1970. 2a edição. São Paulo: Brasiliense, 1981, n.r. 21.

24 Ibidem.

25 DUARTE, Rogério. Momentos do Movimento. Depoimento cedido à Ricardo Muniz, 1987. In.: COHN, Sergio. Encontros: Rogério Duarte. 1a edição. Rio de Janeiro: Beco do Azougue, 2009. p.110. 
É basilar compreender que os movimentos da juventude no Norte global estavam imersos em uma realidade política distinta do Brasil. $\mathrm{O}$ autoritarismo vigorava de certo modo nos Estados Unidos, que via a Guerra do Vietnã pela televisão, ou da Europa que vivia um relativo estado de bem-estar social. No mesmo tempo em que a ditadura brasileira promovia uma agitação, buscava silenciar a produção cultural; resultado de um poder que, como sugeriu Foucault, não é sempre manifestado em forma de proibição, mas como uma rede produtiva que atravessa o corpo social, fazendo com que seja repressor ao mesmo tempo em que é produtor ${ }^{26}$. Nisso, as preocupações com o corpo, com o comportamento e subversões de valores tomavam espaço e criou-se uma radicalização de crítica comportamental em uma época em que as informações sobre a contracultura chegavam ao país. $\mathrm{Na}$ resistência ao controle autoritário, abraçaram-se temáticas correspondentes aos grupos marginalizados e a liberdade em um sentido amplo. Os artistas identificavam-se com as minorias: o negro, o homossexual, o menino do morro, o marginalizado; o marginal ${ }^{27}$.

Rogério, outrora um rapaz que perambulava pela elite intelectual da zona sul carioca, inclusive com um relativo sucesso financeiro, começou a se identificar com os passistas da Mangueira e com os moradores das favelas cariocas. Processo parecido aconteceu com o artista Hélio Oiticica que ainda em 1964 visitou o Morro da Mangueira no Rio de Janeiro, onde ele trabalhou com seus parangolés com as frases "Incorporo a revolta", "Da adversidade vivemos". Em correspondência a artista Lygia Clark, Oiticica Ihe disse que: "hoje eu estou à margem do marginal, não o marginal com aspirações da pequena burguesia, o que acontece com frequência, mas realmente nas margens: na margem de tudo, o que me dá uma surpreendente liberdade de ação"28.

A partir das manifestações de Rogério e Oiticica, compartilho com Frederico Coelho a ideia de que assumir-se enquanto um artista marginal, com uma proposta estética desviante, fora do eixo reconhecido, era uma posição consciente, não um ideal romântico ${ }^{29}$. O artista marginal dos anos 1970 é

26 FOUCAULT, Michel. Microfísica do poder. 12. ed. Rio de Janeiro: Graal, 1996, p.8.

27 DUARTE, Op.cit, 2003, p.89.

28 OITICICA, Hélio. [Carta] 15/10/1968. Rio de Janeiro [para] CLARK, Lygia. 15 f. In.: FIGUEIREDO, Luciano (org.). Cartas. Rio de Janeiro: UFRJ, 1996.

29 COELHO, Frederico. Eu, brasileiro, confesso minha culpa e meu pecado: Cultura 
geralmente pensado e representado de duas formas distintas: a do marginal enquanto artista que rejeitava a produção oficial, produzida pelo governo ou pela indústria cultural; e a do marginal que incorporava em sua obra a angústia e o desespero de um "vazio cultural". Resistente, alienado, maldito, desbundado, e dentre outros adjetivos, o artista marginal desenvolveu a sua própria sobrevivência intelectual e estética, desenvolvendo o seu próprio espaço de livre criação fora dos circuitos sujeitados às normas sociais e modelos formais de trabalho ${ }^{30}$.

Este isolamento, imagino, decorre de um medo de se expressar livremente e sofrer as consequentes penalidades em um Estado vigilante e autoritário. Assim, o artista rompia com a produção cultural que articulava com a união Estado-indústria e acabava produzindo nas margens. Assumia-se uma posição: nós estamos marginais. Estavam, pois a estratégia da cultura marginal era passageira e decorrente de um momento histórico, e não uma posição definida ad infinitum. A instatisfação e não-adequação eram fatores de aproximação entre artistas marginais.

A temática marginal foi abordada em 1970 por Rogério Duarte em dois de seus poemas: "Marginália", que estava em uma caixa em que Rogério ateou fogo quando estava na cidade de seu pai, o qual ele lembrou-se dos versos que havia escrito e "Rock'n Roll na Idade da Pedra". Ele entendia que durante os anos 1970 ele tinha se voltado mais para o rock, tanto para ouvir quanto para escrever letras: "com toda aquela contracultura, me tornei um músico de rock (...) um exemplo típico no Brasil do que eu chamaria o 'artista underground'”, ele disse ${ }^{31}$.

Falando em underground, este era o nome da coluna de Luís Carlos Maciel, um dos porta-vozes da contracultura no Brasil. Maciel publicava sua coluna no jornal $O$ Pasquim, e uma de suas temáticas principais eram as correspondências de Caetano Veloso em seu exílio londrino. O Pasquim teve grande relevância quanto a difusão de informações a respeito da contracultura no geral:

marginal no Brasil das décadas de 1960 e 1970. 1a edição. Rio de Janeiro: Civilização Brasileira, 2010. p.172.

30 Ibidem, p.6.

31 DUARTE, Op.cit, 1997. 
[...] além de introduzirem no Brasil temáticas da contracultura, alguns de seus protagonistas experimentaram drogas, em especial o LSD, em busca de novos modos de percepção. "O Pasquim", ao lado de suas raízes no nacional-popular, instituiu o culto da cultura underground norte-americana, e ainda detonou um movimento próprio de contracultura, transformando a linguagem do jornalismo e da publicidade, e até a linguagem coloquial ${ }^{32}$.

O Pasquim tinha uma tiragem de aproximadamente duzentos mil exemplares semanais disseminando informações sobre cultura no geral, além de temas como LSD, budismo e literatura beat, a qual os jornalistas assumiam ser assuntos pertinentes aos jovens americanos e ingleses ${ }^{33}$. O número de leitores d'O Pasquim coincide com o crescimento do mercado editorial brasileiro do final dos anos 1960 e começo dos anos 1970, em que os bestsellers eram “Marx, Mao, Guevara, Débray, Lukács, Gramsci, James Joyce, Herman Hesse, Norman Mailer e, claro, Marcuse"34.

Entre 1964 e 1985, mais de 150 periódicos foram produzidos, abordando contracultura e política brasileira ${ }^{35}$. Nos anos 1970, foram criados diversos jornais de contracultura no país, sendo o Flor do Mal, com a direção criativa de Rogério Duarte, um deles.

\section{"O mal da flor"}

Embora impressa e editada pela Pasquim Empresa Jornalística S/A, Flor do Mal teve o seu projeto gráfico e editorial distinto d'O Pasquim. Embora fosse um jornal alternativo, O Pasquim era um impresso relativamente tradicional, feito por jornalistas e demais profissionais da área da comunicação. Flor do Mal era experimental, uma colagem de poesias, com a participação de artistas jovens. A sua primeira edição - a única realizada por Rogério Duarte - foi recebida

32 KUCINSKI, Bernardo. Jornalistas e Revolucionários: nos tempos da imprensa alternativa. 1a edição. São Paulo: Editora Página Aberta, 1991. p. XV.

33 Vide Tite Lemos (16 jun. 1971, p.21): « pelo Budismo é naturalmente um interesse diletante, digamos, e vive mais do consumo de certas expressões popularizadas por Watts ou Ginsberg (ou Lennon ou Harrison) e colhidas do rico e poético vocabulário budista, do que de um aprofundamento nas suas fontes originais».

34 VENTURA, Zuenir. 1968: o ano que não acabou. Rio de Janeiro: Nova Fronteira, 1988. p.54.

35 KUCINSKI, Op.cit, p.5. 
com o comentário de um psiquiatra: "esse seu jornalzinho aí é igualzinho ao que os malucos da minha clínica faziam como terapia"36 (Fig. 1):

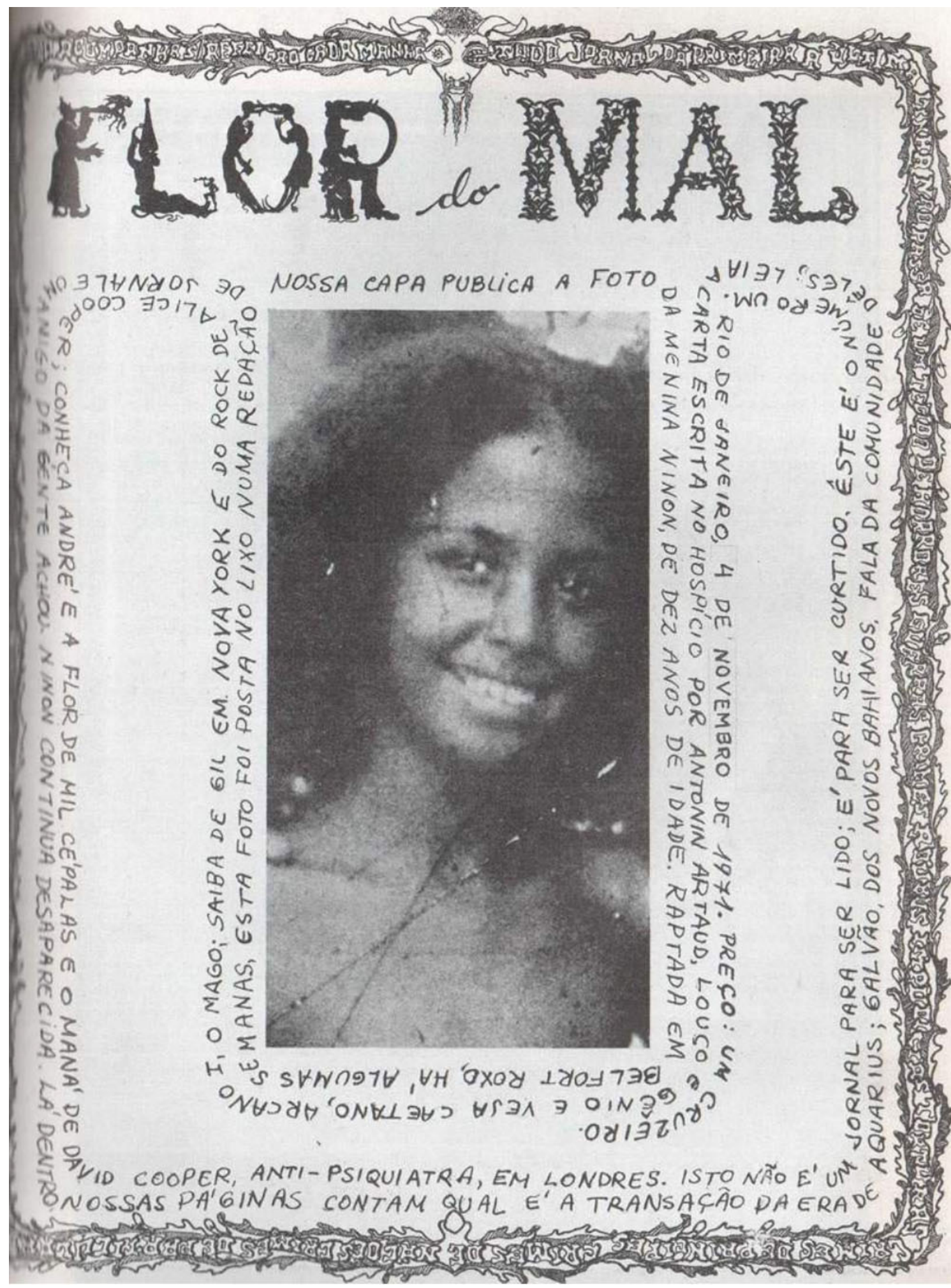

36 MACIEL, Luís Carlos. Geração em transe. 1a edição. Rio de Janeiro: Nova Fronteira, 1996. p.246. 
A capa traz o retrato de uma jovem negra; personagem que dificilmente estamparia uma revista de alta circulação. A foto foi encontrada no lixo por Torquato Neto, que propôs que ela fosse utilizada na capa . A menina aparece na foto sorrindo, com poucas roupas e de cabelos soltos, olhando para algo que não é o fotógrafo. Seu rosto é emoldurado com frases escritas à mão de uma maneira em que o leitor deve pegar a revista e manipulá-la conforme avança sua leitura. A forma produzida pelo texto guia-se pela fotografia da menina e pelas margens da revista, compondo uma forma semi-retangular, informando ao leitor o conteúdo da revista:

Nossa capa publica a foto da menina Ninon, de dez anos de idade raptada em Belfort Roxo, há algumas semanas, esta foto foi posta no lixo numa redação de jornal de um amigo da gente achou. Ninon continua desaparecida. Lá dentro nossas páginas contam qual é a transação da Era de Aquarius; Galvão, dos Novos Baianos, fala da comunidade deles; leia a carta escrita no hospício por Antonin Artaud, louco e gênio e veja Caetano, Arcanjo I, o Mago; saiba de Gil em Nova York e do rock de Alice Cooper; conheça o André a flor de mil ce'palas e o mana' de David Cooper, anti- psiquiatria em Londres. Isto não é um jornal para ser lido, é para ser curtido. Este é o número 1, Rio de Janeiro, 4 de novembro de 1971. Preço: um cruzeiro ${ }^{37}$.

Para a palavra "Flor", corpos humanos entrelaçados com objetos criam as letras. Um mago estende a sua mão e observa em uma luneta um ser diabólico. Ao seu lado, um ser de chapéu e rabo tem um humano aos seus pés. Criaturas conectam suas cabeças uma a outra, bem como os seus pés enquanto um homem aparece sentado em uma figura diabólica. Para "Mal", flores. Os tipos são semelhantes às capitulares medievais. Emoldurando a revista, escrito em letras distorcidas está descrito:

Todo jornal da primeira a última linha não passa de um tecido de horrores guerras crimes roubos torturas crimes de príncipes crimes de nações crimes de particulares uma embriaguês de atrocidade universal e deste aperitivo repugnante que o homem civilizado acompanha na refeição de cada manhã ${ }^{38}$.

Essa frase tem suas formas arredondas que se assemelham a folhagens. Marcando o início e o fim da frase, há um demônio com o olho coberto por folhas, com longas barbas, cabelos crespos e um chifre torcido. Há uma série de coincidências entre "Flor do Mal" e os escritos medievais, como 
Rogério havia proposto na concepção da revista. Considerando a distância cronológica e espacial da Alta Idade Média e do Brasil dos anos 1970, mas acatando a ideia de Rogério Duarte de promover uma revista feita à mão nos moldes medievais, há a criação de "nuanças místicas e espirituais"39 em Flor do Mal. Seus produtores assumiam-se como marginais, isolandose, ao mesmo tempo em que debatiam e discutiam assuntos também relativos a religiosidade e espiritualidade. Rogério começou uma "guerrilha espiritualista" nos anos 1970, com seus contatos com o hare krishna, o budismo e a cultura védica ${ }^{40}$.

Inspirado em Charles Baudelaire, mais especificamente no livro "As flores do mal" (1857), conectados ao existencialismo francês, os colaboradores de Flor do Mal entendiam que eram "totalmente responsáveis por tudo o que faziam, inclusive as obras de arte"41. Desejando que seus discursos não fossem como uma transgressão proposital, mas sim por uma necessidade de ordem existencial, a liberdade era tomada como principal base de suas criações.

A crise existencialista juntamente com a efervescência de seu conteúdo, fez com que Flor do Mal fosse aclamada nos círculos mais radicais da contracultura, ao mesmo tempo em que era objeto de repugnância fora desses círculos ${ }^{42}$. Repugnância, penso, porque ela distoava da imprensa alternativa em um geral, sobretudo as que abordavam temáticas como música e comportamento. Mesmo O Pasquim ou O Bondinho, próxima dos tropicalistas e que debatia sexualidade, psicanálise e repressão, eram feitas por jornalistas, críticos e com uma escrita bastante distinta da Flor do Mal; o semelhante acontecia com o seu projeto gráfico (FIGURA 2):

Em $O$ Pasquim há charges e fotografias, com um projeto gráfico que inverteu a lógica de chamar a atenção para as reportagens, utilizando charges e fotos como elementos complementares; a ilustração não ficava

39 MEGGS, Philip; PURVIS, Alston. História do Design Gráfico. 1a edição. São Paulo: Cosac Naify, 2009. p.64.

40 DUARTE, Diogo. Entrevista com Isabela Fuchs. Rio de Janeiro, 10 fev. 2017. In.: FUCHS, Isabela Marques. Design gráfico e resistência cultural em Rogério Duarte (1962 - 1971). 2018. 203f. Dissertação (Mestrado em História) - Universidade Federal do Paraná, 2018.

41 MACIEL, Luís Carlos. Anos 60. Porto Alegre: L\&PM, 1987. p.27.

42 CABO, Op.cit, p.8. 
Figura 2

Capas das revistas

"O Pasquim" e

"Bondinho". 1971.

O Pasquim, n.84.

Rio de Janeiro. 11

a 17 fev. 1971;

Bondinho, s/n. Rio

de Janeiro, 9 a 22

dez. 1971
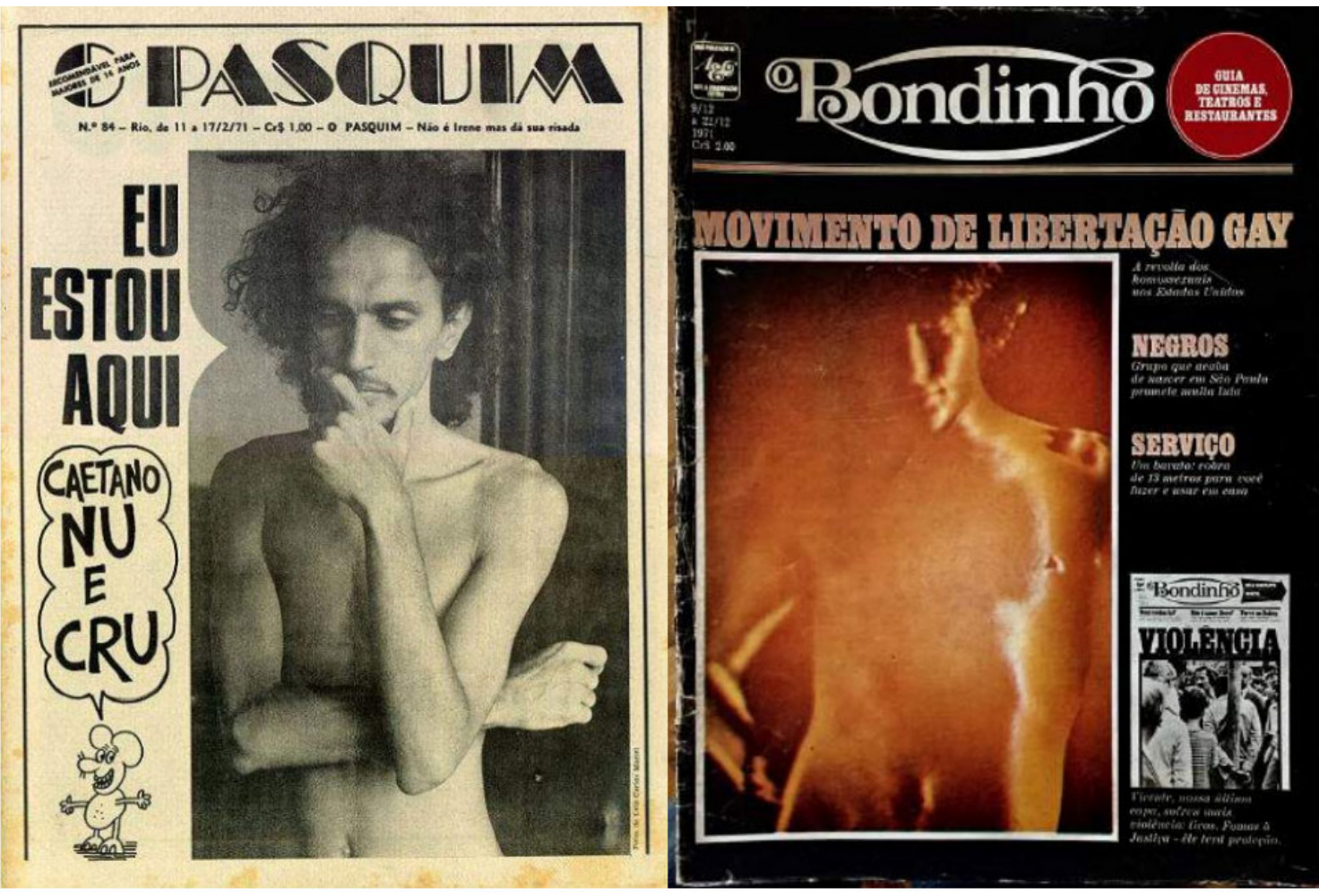

subordinada ao texto. Em $O$ Bondinho há uma grande quantidade de elementos visuais: uma fotografia colorida, chamadas por reportagens e a capa da edição anterior.

O miolo de Flor do Mal, projetado por Rogério Duarte, as páginas mesclam recortes de fotografia e relatos pessoais escritos à mão (Fig. 3):

O texto que Galvão dos Novos Baianos escreveu para a revista está ao lado de retratos colados da banda. Luas e nuvens, recortes aleatórios, fazem uma montagem da vida cotidiana da banda, com roupas no varal e cafés da manhã, em uma espécie de álbum de família. Parecido com o diário de um adolescente, que narra sobre seu dia-a-dia e cola imagens relativos a ele. As páginas dos textos $O$ mito do andrógino e Ser criança, namorar, passear utilizaram-se de colagem fotográfica, ilustração, caligrafia e tipografia (Fig. 4):

Com fotos ovais e um recorte à mão, jovens de longos cabelos aparecem tocando flautas, junto com mulheres com saias longas ao meio da natureza. $\mathrm{O}$ texto vai de encontro aos títulos e às molduras. À mão, a caligrafia do título foi feita com traços grossos, fazendo parecer que foi adicionada depois da composição original do restante da matéria. O título encosta 
de todos. Harilhona (Bolota) quando nas tó "musando" Moxura, tá comendo docé e outros i: nimigos da boucobiótea. Dó tranquilo como nos borns tempos da Bahia. OBarbudo transando de dia ede noi te os shows, abrundoo mereado das formas mais criativas.

"Foi na bapa que en masei, loueo! Jransfor more-se ate num vagabundo. Palarea, quasca. ceitic o cons cho. Rita, prèta, preanha"; eis ac o som permanente mas paradas, nos alto-falantes da eidade. Judo isso depais da etegada de fo. â Gilberto.

Já tudo bem. Nos estamos bem pela flor do Mal. Claro, nós so mos da eidade do bem. 6 bem sem nenhum pa comecito. Nos somoso bem e poonto. Fos dizemos as cocsas jeá nós mesmos e tramos nos dijendo ate ná⿱ nos lemhean mos mais. Só sabermos. Getrio (Janazinhto Juppidasä)

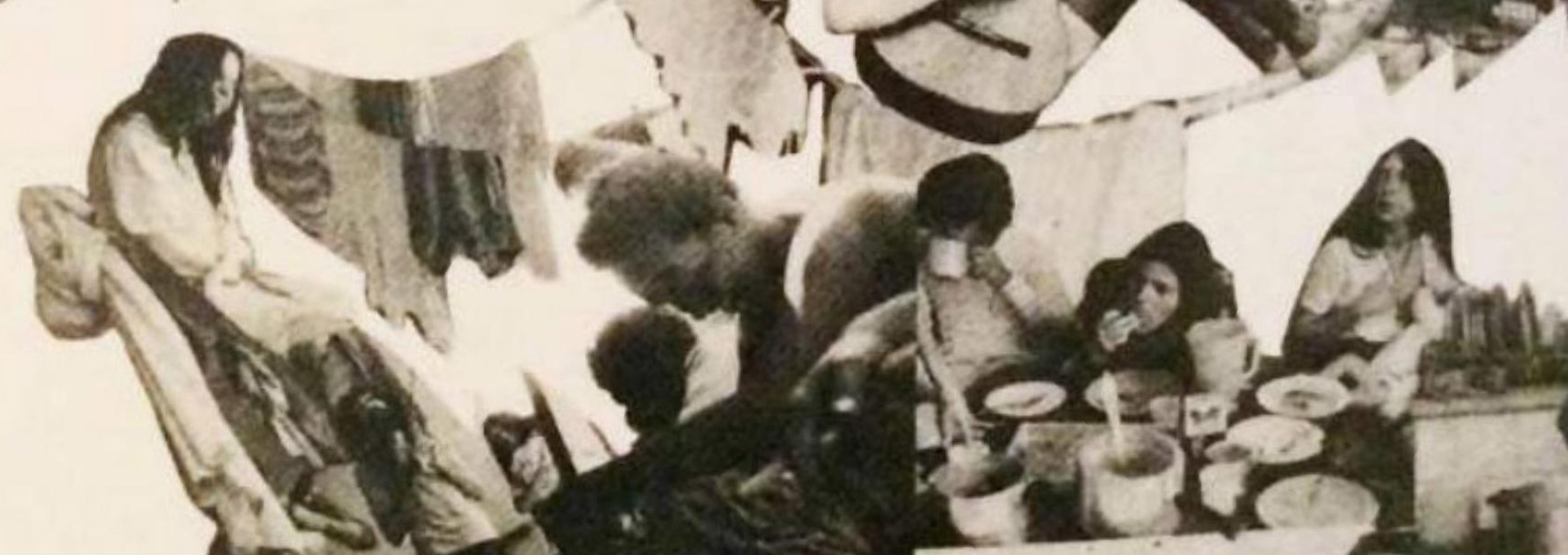




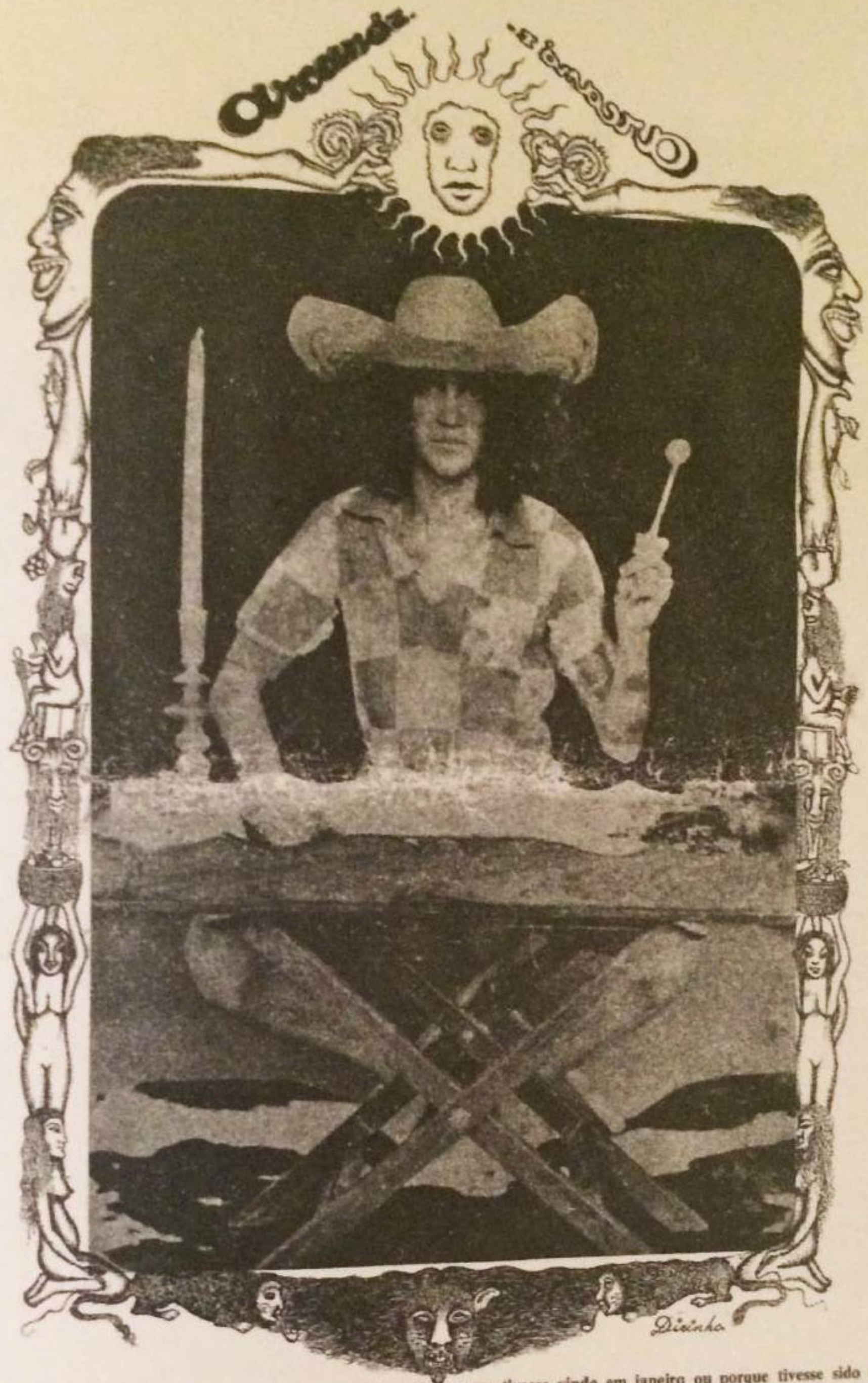

Q Qual te e Arcano do Cactano? Eu o chamei de primeiro nâo p̧ porque tivesse vindo é ó derradeiro. Mistérios sảo todos: o quarto riobado que bouvesse om primeiro. Basta perguntar ao louco que eu náo sei se é derradeigo Mavam todos cantando. Para se

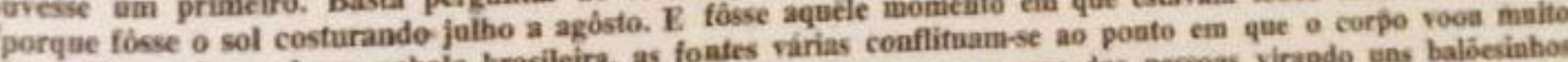


com o design racionalista na sua diagramação e apresentação gráfica ${ }^{43}$. O projeto gráfico de Flor do Mal foi realizado em um período em que os debates sobre Design estavam atrelados ao desenvolvimento cultural e, sobretudo, industrial do país. Criada no borbulho das duas últimas Bienais de Desenho Industrial - em 1970 e 1972, realizadas no Rio de Janeiro - o projeto gráfico de Flor do Mal definitivamente não tinha conexões projetuais com o racionalismo "coerente com a política genericamente irresponsável do milagre econômico"44, que continuavam valorizadas no começo dos anos 1970. Parecer ser um jornal feito por "malucos" era um elogio para Rogério Duarte. Tanto que ele foi à Companhia do Disco solicitar patrocínio para a execução da revista, com o que lhe responderam: "Coisa hippie? Tô fora!"45. O artesanal da Flor do Mal ia de encontro às propostas dos hippies, que comercializavam suas roupas, acessórios e poesias feitos à mão em praças e feiras.

Mesmo que fosse impressa em uma gráfica de grande porte, "Flor do Mal" tinha algumas características de um fanzine, publicação alternativa e artesanal feita por e para fãs de determinada temática com a intenção de propagação de ideias que não são vinculadas às mídias tradicionais. $\mathrm{O}$ zine tem como uma de suas principais características a sua produção, com a diagramação, composição, divulgação e distribuição realizada pelos seus próprios editores, fora de uma circulação padrão.

Flor do Mal ficava à margem da grande mídia, o que para Rogério Duarte e seus outros produtores era ótimo. Ela teve mais outras quatro edições, com datas de publicação irregulares e foi encerrada por falta de vendas. Textos místicos, hedonistas e de temática messiânica não eram produzidos apenas por Flor do Mal. Dentro da ampla gama de impressos alternativos, posso citar dois exemplos. O jornal O Vapor (1973) produziu uma matéria sobre o estilo de vida cigano; $O$ Bondinho tinha vasto conteúdo relativo à libertação sexual, com ênfase ao pensamento de que a repressão sexual era a mãe de todas as repressões ${ }^{46}$.

43 MACIEL, Op.cit, 1996. p.247

44 SOUZA, Pedro Luiz Pereira de. ESDI: biografia de uma idéia. Rio de Janeiro: EdUERJ, 1996. p.211.

45 BARROS, Patrícia Marcondes. O Poder da Flor. Disponível em: < http://www. dopropriobolso.com.br/index.php/artes-\%20visuais/54-artes-plasticas/617contracultura-o-poder-daflor-do-mal>, 2008. Acesso em: $1^{\circ}$ de abril de 2020.

46 KUCINSKI, Op.cit, p.51. 
O projeto visual que Rogério Duarte realizou para Flor do Mal, inserido no quadro de referências da cultura marginal, foi um de seus projetos gráficos mais radicais. Não era uma revista para ser lida, mas para ser contemplada. Em vez de ler sobre Caetano, a proposta era observar os desenhos e ler os textos na intenção não apenas de informar-se, mas de contemplar, de receber a proposta gráfica da revista com "extrema receptividade" ${ }^{4}$. Se Pareyson nega a contemplação enquanto algo passivo, Rogério não acreditava em uma contemplação desinteressada mas sim no contato íntimo entre sujeito e objeto - o uso.

A radicalização mística em Flor do Mal vem em conjunto com a ideia de que o design está conectado à cultura, sinalizando suas manifestações. O designer, a partir de práticas, pensamentos, debates e circunstâncias, desenvolve seus projetos, articulando visualmente as mensagens que são concebidas preliminarmente ${ }^{48}$. O contexto da Marginália, com suas correspondentes atuações, estratégias e conflitos, abriu espaço para a produção da Flor do Mal, elemento de síntese tanto da radicalização de Rogério nos anos 1970, quanto das propostas marginais.

\section{Últimas palavras}

Fruto da potência inventiva de seus produtores, Flor do Mal também é resultado de suas vivências, particularidades e olhares de mundo. Falar de marginália é, de fato, falar em experiências e, por consequência, falar do experimental. Embora circunscrito em um contexto autoritário e repressivo, que via de regra deveria apagar a chama acesa das produções contraculturais, Flor do Mal é resultado dessas fluências e influências dos "anos de chumbo". Apenas um apontamento: Flor do Mal, assim como qualquer produto cultural que não ia de encontro com os interesses dos militares, não driblava a ditadura, mas trazia uma forma de suportar. A resistência cultural dos vinte e um anos da ditadura militar brasileira trabalhaa com esses impasses, criava escopos criativos possíveis. Flor do Mal não é um elemento heróico capaz de desestabilizar um aparelho autoritário, mas é um elemento que dialogou, por vezes contraditoriamente, com as circunstâncias em que esteve inserido.

47 PAREYSON, Luigi. Os problemas da estética. São Paulo: Martins Fontes, 2001. p.206.

48 GRUSZYNSKI, Ana Cláudia. Design gráfico: do invisível ao ilegível. Rio de Janeiro: 2AB, 2000. p.7. 
A figura de Rogério Duarte é o de um então rapaz, calejado pelas suas experiências perante um Estado altamente autoritário, que se assumia enquanto um agitador, que durante o início da década de 1970 trabalhava nas margens e nas brechas que o sistema deixava. Consideramos que é imprudente separar a vida e a visualidade de Rogério Duarte. Seus projetos gráficos são fruto de sua mentalidade pós-traumática. Isso não significa um romantismo frente aos terrores que ele sofreu, mas sim um olhar atento em suas configurações formais atreladas à espiritualidade, à poesia, à religiosidade que ele se apegou durante este período.

Resultado das experiências contraculturais de um conjunto de jovens artistas, um apelo à fruição e ao deleite estético. Os recortes e palavras soltas de Flor do Mal são uma colagem da marginália brasileira; experimental, confessional e inventiva. 